\title{
FÓRUM DE JACAREÍ: UMA RELÍQUIA MODERNISTA ABANDONADA NO CENTRO DA CIDADE
}

\section{ARTIGO ORIGINAL}

NIEMEYER, Carlos Augusto Da Costa ${ }^{1}$

NIEMEYER, Carlos Augusto Da Costa. Fórum de Jacareí: Uma relíquia modernista abandonada no centro da cidade. Revista Científica Multidisciplinar Núcleo do Conhecimento. Ano 04, Ed. 12, Vol. 05, pp. 05-15. Dezembro de 2019. ISSN: 24480959, Link de acesso: https://www.nucleodoconhecimento.com.br/arquitetura/reliquia$\underline{\text { modernista }}$

\section{RESUMO}

O presente artigo busca iluminar um estudo de caso de um remanescente da arquitetura modernista paulistana, hoje quase despercebido no centro da cidade de Jacareí, estado de São Paulo, atualmente em processo contínuo de descaracterização, já querendo desaparecer da memória da cidade. O prédio do Fórum de Jacareí do alto de seus quase 60 anos de existência nos conta uma história de prestígio e valor que seu estilo arquitetônico já deteve identificado com o momento de ascensão das estruturas urbanas do estado e do país e a aura de progresso que a obra modernista emprestava. Nessa perspectiva, o artigo traz à luz a emergência da necessidade de preservarmos nosso passado de forma a resguardarmos nossa história, e por assim dizer, a própria identidade da cidade. O estado crítico dessa notável obra é testemunho relevante de um patrimônio modernista do estado que clama por apoio em meio à expectativa sombria que se desenha em torno de seu uso e apropriação por quem deveria em tese resguardá-la.

\footnotetext{
${ }^{1}$ Arquiteto, Mestre em História pela FAU-USP (2001) e Doutor em Tecnologia e Cidade pela Unicamp (2015).
} 
Palavras-chave: Patrimônio, arquitetura, preservação.

\section{INTRODUÇÃO}

Este trabalho tem como elemento motivador um olhar crítico sobre o estado de uma obra pública notável existente em Jacareí, remanescente do estilo modernista, entregue hoje a um processo contínuo de descaracterização e abandono, e assim condenado ao esquecimento: o Fórum da cidade.

Ao debruçarmos sobre a imagem do Fórum de Jacareí, vislumbramos um remanescente que reflete em grande estilo a assimilação do movimento arquitetônico modernista no Brasil, cujas linhas estético-construtivas mostram a poética que guiava sua intenção plástica. Esta linguagem moderna de particularidades nacionais, gerada a partir da vertente funcionalista francesa criada pelo teórico franco-suíço Le Corbusier (1887-1965) e magistralmente conduzida por uma notável geração de profissionais brasileiros de renome do campo da arquitetura e da construção civil, contribuiu para a disseminação de modelos icônicos que seriam reproduzidos em larga escala nas cidades brasileiras.

Essa vanguarda profissional foi responsável por criar uma "escola" de arquitetura moderna genuinamente brasileira com que nos deu visibilidade e respeito, consagrando definitivamente nossa arquitetura no cenário mundial. Muito dessa notável produção arquitetônica encontra-se fora dos grandes centros, mas projetadas com a mesma virtuosidade estética que marcou seus paradigmas mais ilustres. Contudo, nem todas receberam um merecido reconhecimento à altura do valor afetivo e arquitetônico que possui na história da cidade. Esse é o caso do Fórum de Jacareí, uma obra pública notável, projetada com maestria, que merece nossa atenção diante da crescente descaracterização que lhe é imposta proporcionando um futuro incerto a uma obra que pede maior valorização no patrimônio afetivo da cidade. 


\section{A DISSEMINAÇÃO DE UM ESTILO}

A arquitetura moderna eclodiu simultaneamente na Europa e nos EUA no início do século XX por obra de alguns arquitetos visionários, em convergência com os demais campos culturais (literatura, artes plásticas etc), encerrando a fase eclética das artes e enaltecendo novos caminhos desapegados do passado. Ainda que aparentemente se mostre igual em todos os lugares, daí derivando o termo International Style, acabando por revelar-se um modismo por todo o ocidente, na verdade encerra particularidades e padrões locais de acordo com o progresso científico-tecnológico da engenharia local. Dentre seus principais protagonistas, o arquiteto franco-suíço Le Corbusier se destacou como o maior influenciador do modelo arquitetônico modernista adotado em larga escala no Brasil a partir dos anos 1930, de inspiração cubista explorando as potencialidades plásticas do concreto.

A consagrada arquitetura moderna nacional, reconhecida como foco de inovação a nível mundial a partir dos anos 1940, provocou também um grande avanço nas estruturas pedagógicas das escolas de belas artes, de arquitetura e de engenharia do país, a exemplo da ENBA do Rio de janeiro (mais tarde Faculdade Nacional de Arquitetura da Universidade do Brasil) graças ao mestre Lucio Costa, notável propagador da linguagem moderna neste estabelecimento em sua curta estada no início da década de 1930. Fato este que contribuiu muito para o amadurecendo da carreira profissional de arquiteto no Brasil e da consagração do novo estilo de composição que aqui encontrará solo fértil.

Segundo Segawa (1998), foi decisivo para a aplicação dos novos paradigmas da arquitetura moderna no Brasil a expansão de faculdades de arquitetura por todo país difundindo conhecimento concomitante ao deslocamento de profissionais, seja atuando em docência, seja abrindo escritórios, permitindo a disseminação da nova linguagem. Linguagem esta que dará identidade ao espírito desenvolvimentista que emanava das políticas nacionais de modernização que então se propunha ao país.

Na esteira da notável repercussão internacional que nossa arquitetura alçará por força de nossa primeira geração de arquitetos modernistas capitaneados por Lucio Costa, 
Oscar Niemeyer, Affonso Eduardo Reidy e outros, também, no plano doméstico, darse-á um reconhecimento social sem precedentes à carreira. A disseminação de ideias modernistas, que encontrará seu ápice com a construção de Brasília (1960), permitiu assim consolidar a afirmação de uma hegemonia estético-cultural-arquitetônica formulada a partir dos principais centros irradiadores, Rio de Janeiro e São Paulo, expandindo a todos os lugares uma práxis arquitetônica de grande aceitação e reconhecimento popular. Elementos formais dessa arquitetura, como rampas, elementos vazados, transparências, grandes vãos, formas cubistas e ousadas, acabaram sendo apropriados e utilizados vastamente pelo país por legiões de arquitetos e construtores.

Muitos prédios públicos foram concebidos nesse contexto desenvolvimentista vigorado no país entre os anos 1940 e 1970 e que possibilitou erguer hospitais, escolas públicas, campus universitários, fóruns, prefeituras entre outros equipamentos urbanos, cuja intensa migração de profissionais pelo país proporcionará troca de conhecimento e de tecnologia em arquitetura e construção (SEGAWA, op. cit). O Fórum de Jacareí retrata esse período de entusiasmo nas políticas públicas e que teve seu auge no Plano de Ação patrocinado na gestão operosa do governador Carvalho Pinto (1959-1963) responsável pela contratação de muitos arquitetos para executar centenas de obras no campo da administração, saúde e educação por todo o estado, com liberdade para trabalharem em "conformidade com o ideário moderno brasileiro" (CORDIDO, 2008).

\section{O FÓRUM DE JACAREÍ: REFLEXO DE UMA CULTURA MODERNISTA}

O projeto do Fórum de Jacareí é de autoria do arquiteto-urbanista Ney Marcondes (1923 -2019), natural de São Bento do Sapucaí, leste paulista. Filiado cedo à vertente modernista, Marcondes foi autor de projetos de grande visibilidade por todo o estado de São Paulo como o Parque do Trajibu, em Pindamonhangaba (SP), parque temático inspirado na identidade indígena, e coautor no projeto da sede do Banco Nacional da Habitação (BNH), na praça Roosevelt, centro de SP, uma concepção arquitetônica 
ousada com grandes vãos livres nos "pavimentos tipo". Sua produção foi vasta, indo de projetos de habitação popular a equipamentos públicos, edifícios corporativos e residenciais.

Egresso do prestigioso curso de arquitetura e urbanismo da paulistana Faculdade Mackenzie, onde formou-se em 1954, Ney Marcondes foi contemporâneo na faculdade de grandes nomes da chamada "escola paulista" de arquitetura que teve expoentes como Paulo Mendes da Rocha, Oswaldo Bratke, Fábio Penteado, Alberto Botti, Marc Rubin, Joaquim Guedes, Jorge Wilheim entre outros, bebendo na mesma fonte desta notável falange de representantes da arquitetura nacional, da qual fez parte. Projetos seus foram destaque na VI Bienal de Arte Moderna de São Paulo (1961) que aconteceu conjuntamente com a Exposição Internacional de Arquitetura daquele ano, atestando a importância desse arquiteto.

A identidade da assim chamada "escola paulista de arquitetura" deve-se a uma linguagem com ênfase na tecnologia da construção: ora na adoção do concreto armado aparente, grandes vãos, extensos planos horizontais e na pré-fabricação de componentes, um dos pilares da tecnologia construtiva moderna da qual Ney Marcondes soube tão bem atuar. A ousadia formal dos jovens arquitetos paulistas constituirá, assim, um paradigma de qualidade que responderá muito bem aos desafios e anseios do nacional-desenvolvimentismo brasileiro.

O prédio do Fórum de Jacareí é um exemplo marcante neste escopo de obras que bem representam o período de expansão das estruturas urbanas no estado de São Paulo e que envolveu jovens e talentosos arquitetos, como Ney Marcondes, no planejamento de uma estrutura edilícia na linguagem moderna para a justiça estadual: Fábio Penteado (Fórum de Araras), Paulo Mendes da Rocha (Fórum de Avaré), Joaquim Guedes (Fórum de Itapira), Jorge Wilhen (Fórum de Orlândia), Oswaldo Bratke (Fórum de Avaré), Vilanova Artigas (Fórum de Promissão), só para citar alguns arquitetos emblemáticos.

O Fórum de Jacareí situa-se na atual Praça dos Três Poderes, centro de Jacareí, espaço urbanístico que também abriga os demais prédios que compõe o poder público 
da cidade, a Prefeitura e a Câmara Municipal, em lote amplo no encontro das ruas Capitão José de Macedo com a Quinze de Novembro. A obra foi concluída em 1965 e possui 03 (três) pavimentos com uma área total edificada de $3.120,00 \mathrm{~m} 2$.

Foi projetado como assim exigia os preceitos modernistas que buscavam "reinventar" funcionalmente e esteticamente a cidade negando seu passado eclético. Por este aspecto, "as fachadas são então encaradas como uma resultante das necessidades concretas de funcionalidade do edifício" (MENDONÇA, 2011), favorecendo necessidades humanas primordiais ligadas a higiene como a ventilação, o verde e acesso franco a luz. Assim, o "vazio" ao entorno da arquitetura não é um mero capricho do projetista ou um espaço ocioso, pelo contrário, faz parte do projeto de inovação modernista, permitindo assim um maior contato com a natureza, ideário herdado da experiência predecessora das "cidades-jardins" do final do século XIX, que depois inspiraria "bairros-jardins" em diversas cidades do mundo com esse mesmo propósito. A natureza passa a fazer parte do ideário da cidade modernista e a arquitetura concomitantemente passa a ser funcional, arejada, acolhedora e humana.

Assim, sua implantação, corolário desta configuração precedente, também remete a esse ideário, ensejando implantação generosa tratada paisagisticamente, com acessos elegantes, gerando áreas de respiro, luz e ventilação para seu interior. Seu formato retilíneo em bloco único ressalta uma horizontalidade repousante sobre a relva acolhedora conforme previa a cidade modernista, oferecendo o equilíbrio e a dignidade necessária que deve emanar de um prédio da justiça. Certamente foi essa a intenção do arquiteto.

Seu volume principal em ligeiro balanço sobre um discreto embasamento valoriza a diretriz horizontal e o imenso pano de elemento vazado ("cobogós") ali colocado como recurso na contenção da insolação sem impedir as brisas dominantes, um dos grandes legados de solução arquitetônica da modernidade brasileira. O "cobogó" é uma invenção brasileira surgida na década de 1920, em Recife, criado por um grupo de engenheiros, inspirado nos muxarabis da arquitetura árabe: o português Amadeu Oliveira Coimbra, o alemão Ernesto Agusto Boeckmann e o brasileiro Antônio de Góis. O termo cobogó é a combinação da primeira sílaba do sobrenome dos três 
engenheiros. O elemento vazado foi amplamente divulgada ao mundo por nossa primeira geração de arquitetos modernistas (Fig. 1).

Fig. 1. Exemplos do legado brasileiro no uso funcional e elegante dos cobogós, respectivamente, por Lucio Costa (Rio de Janeiro, 1948), Oswaldo Bratke (São Paulo, 1951), Oscar Niemeyer (São Paulo, 1956).

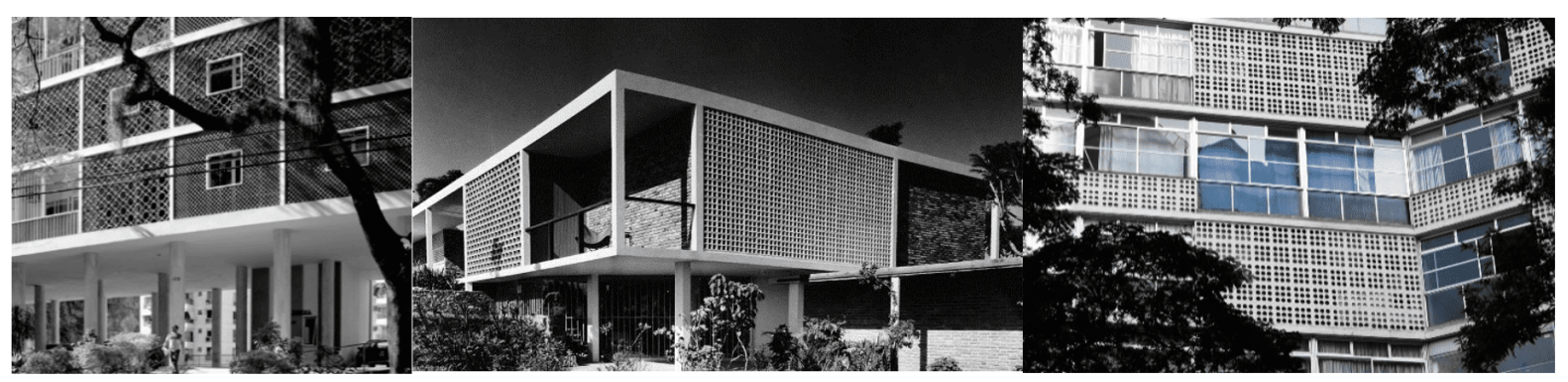

O projeto do Fórum de Jacareí é um bom exemplo de aplicação dos cobogós. Sensível às condições climáticas existentes ao se promover a ventilação natural, algo, aliás, bem em voga nos dias atuais face a necessidade de economia de energia, define uma solução plástica legada assertivamente pelo arquiteto conciliando personalidade e conforto ambiental ao projeto (Fig.2).

Fig. 2. Imagens da inauguração em 1965 com o longilíneo prédio de estética cubista "pousado" sobre generosa área livre como exigia o ideário modernista na tentativa de "reinventar" funcionalmente e esteticamente a cidade. Percebe-se a força plástica e imponente da composição volumétrica da fachada linear ao mesmo tempo que resolve a questão da insolação propiciando conforto ambiental aos interiores. Fonte: Memória pública de SP.

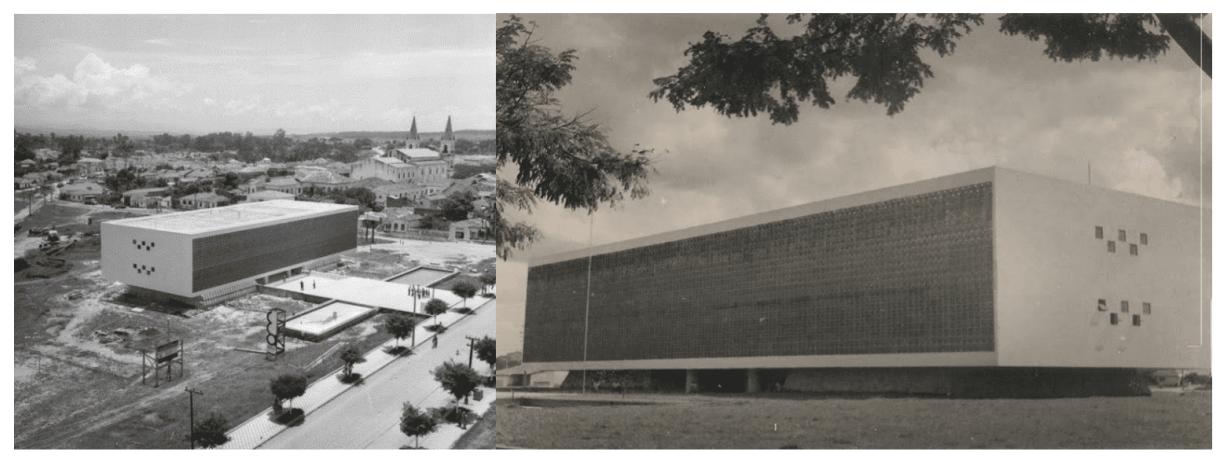




\section{NECESSIDADE DE TOMBAMENTO}

O tombamento de uma obra tem o objetivo de preservar, por meio da aplicação de legislação específica, bens de valor histórico, cultural, arquitetônico, ambiental e também de valor afetivo para a população, impedindo que possam ser destruídos ou descaracterizados. Pode ser aplicado a bens móveis e imóveis de interesse cultural ou ambiental. Somente é aplicado a bens materiais de interesse quando há notório valor para a preservação da memória coletiva. Portanto, o tombamento visa preservar referenciais, marcas e marcos da vida de uma sociedade. Marcos arquitetônicos são um bom exemplo.

Sua conceituação constitucional encontra-se disposta no Artigo 216 da Constituição Federal para a qual: "constituem patrimônio cultural brasileiro os bens de natureza material e imaterial, tomados individualmente ou em conjunto, portadores de referência à identidade, à ação, à memória dos diferentes grupos formadores da sociedade brasileira" onde inclui (item V) os "conjuntos urbanos e sítios de valor histórico, paisagístico, artístico, arqueológico, paleontológico, ecológico e científico".

O tombamento não altera a propriedade de um bem, apenas proíbe que venha a ser destruído ou descaracterizado de forma a se tornar irreconhecível. Seu entorno também deve ser preservado, tendo um perímetro delimitado com objetivo de preservar a sua ambiência e impedir que novos elementos obstruam ou reduzam sua visibilidade. Cumpre destacar que a proteção do patrimônio ambiental urbano está diretamente vinculada à melhoria da qualidade de vida da população, pois a preservação da memória é uma demanda social tão importante quanto qualquer outra atendida pelo serviço público. Diversos estudos em sociologia urbana já demonstraram a inseparável relação entre memória $e$ identidade e, consequentemente, o importante papel da memória como condição fundamental para a construção de identidades culturais urbanas (CAMPANHA \& ALMEIDA, 2018).

Um dos aspectos basilares na vida de uma cidade é o conjunto de recordações que dela emerge em cada arquitetura do passado em que nos deparamos em nosso espaço de vivência. Os artefatos arquitetônicos tornam-se evidencias marcantes 
dessa experiência coletiva e seus habitantes possuidores dessas lembranças e testemunhos, uma vez que a memória se fixa onde o usuário habita. Assim é importante frisar o papel do tombamento de bens imóveis para garantir que essa memória não desapareça da cidade privando seus moradores de uma ligação identitária com seu território, responsável que é por ativar relações de pertencimento e cidadania fundamentais para se construir uma empatia com a cidade.

Nesse contexto, resgata-se aqui o exemplo da Prefeitura de São Paulo ao homologar à decisão do Conselho Municipal de Preservação do Patrimônio Histórico, Cultural e Ambiental da Cidade de São Paulo - Conpresp - em tombar uma série de imóveis assinados por expoentes da nossa arquitetura moderna construídos entre os anos de 1927 e 1980 iluminando seu importante papel na memória recente da cidade. E São Paulo tem história para contar e para preservar. A notícia revela a importância que cada vez mais as obras modernistas detém no imaginário social, isso devido ao fato de que o "modernismo", enquanto estilo, linguagem e signo, é um fato histórico de nosso tempo e por isso muito presente em nossos caminhos e memória.

Contudo, ao olharmos para o atual estado do Fórum de Jacareí (Fig. 3) denota-se o estado de precariedade e descaracterização que o prédio vem sofrendo, chegando ao ponto de não mais ser reconhecido como um testemunho importante da arquitetura moderna da cidade e do estado de São Paulo. Compreende-se a necessidade de atualizações desses espaços arquitetônicos decorrentes dos novos usos solicitados por demandas associadas aos avanços tecnológicos que introduzem continuamente novos equipamentos e redes prediais, além, é claro, do desgaste natural dos elementos construtivos com o passar do tempo. Todavia, é fato que o não entendimento da importância da preservação desencadeia um processo continuo de intervenções espúrias caracterizadas por reformas, ampliações ou supressões estruturais resultando em desfiguração e apagamento da memória. O resultado final disso não é difícil de prever.

Fig. 3. Estado atual do Fórum de Jacareí, desfigurado, sem o pano de cobogós que caracterizava o estilo. Ao fundo o esqueleto de uma anexo espúrio "colado" no prédio 
modernista; as entradas outrora elegantes, viraram estacionamento. Fonte: Imagens do autor.

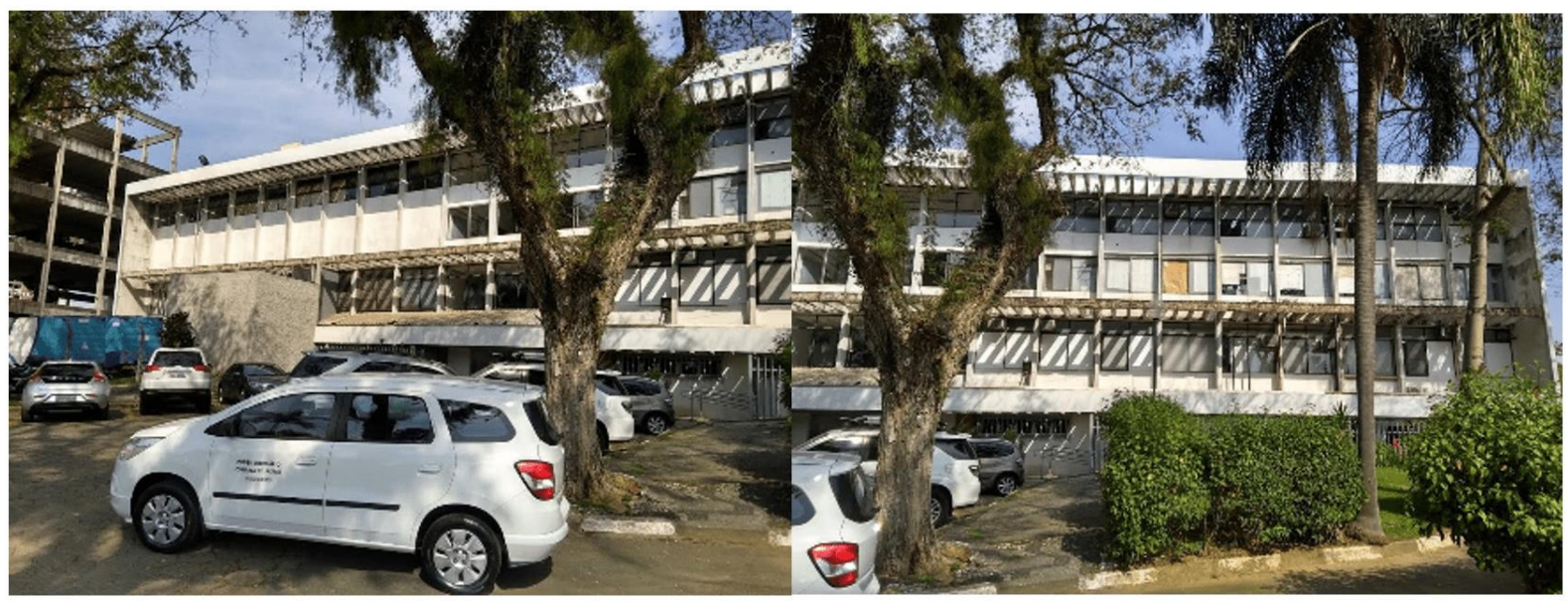

Não importa aqui aventar as razões da necessidade funcional colocada pelo órgão público, mas tão somente a qualidade dessas ações descontextualizadas, fruto de ausência de embasamento técnico e até sensibilidade. Conferir a autenticidade e a importância de um bem arquitetônico como esse para a cidade e o estado é fundamental antes de se propor intervenções físicas, à começar por eleger a coletividade como objetivo e fundamento maior na preservação do bem.

Fig. 4. Tomada aérea da Pça dos Três Poderes nos anos 1970, com o vistoso prédio do Fórum em primeiro plano em sua implantação original em meio ao verde, segundo os preceitos modernistas da qual era signatário. Fonte: Imagem de arquivo.

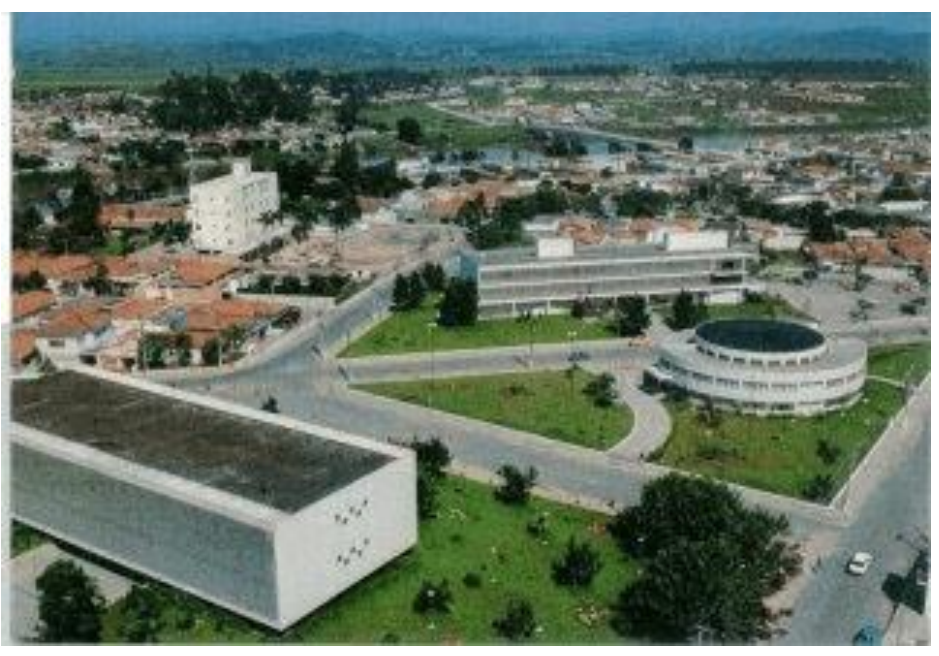




\section{CONCLUSÃO}

Preservar a fachada e o entorno do Fórum de Jacareí através de um "Retrofit" bem conduzido se faz necessário e urgente; há meios técnicos para isso ao qual chamamos de "restauração" (diferente de reforma) dando-lhe uma atualidade tecnológica com a devida preservação de suas características originais, devolvendo a dignidade que o bem público e a cidade merece. A prática do Retrofit é uma realidade que vem sendo difundida no mundo todo para a revitalização de centros urbanos ou reocupação de prédios históricos garantindo sua existência e preservando sua memória.

Assim sendo, é de vital importância para uma sociedade que se pretenda evoluída, que tenha obras culturais e artísticas preservadas, garantindo assim a possibilidade de seus descendentes desfrutarem desse elo de ligação com seu passado. O patrimônio construído quando devidamente preservado é um "ativo urbano" cuja existência é fundamental para manter a identidade e orgulho à cidade.

\section{REFERÊNCIAS}

CAMPANHA, Aline L; ALMEIDA, Eneida, Territórios da fronteira entre memória e história em São Paulo. 217.03 história, ano 19, jun. 2018. Vitruvius: Arquitextos ISSN 1809-6298. Disponível em: https://www.vitruvius.com.br/revistas/read/arquitextos/ 19.217/7021. Acesso em: 22/10/2019.

CORDIDO, Maria Tereza R. L. B. Edifícios públicos. Arquitetura forense: arquitetura moderna questionando a simbologia e mitos do Poder Judiciário no Estado de São Paulo. Revista de pesquisa em arquitetura e urbanismo do programa de pósgraduação do Departamento de Arquitetura e Urbanismo-EESC-USP. São Carlos, 2008. Disponível em: file:///C:/Users/Carlos/Downloads/44722Texto\%20do\%20artigo-53274-1-10-20120924.pdf. Acesso em: 22/10/2019.

MENDONÇA, Dafne M, Arquitetura do Movimento Moderno enquanto estratégia de redesenho nas cidades brasileiras: possibilidades e limitações. 9o Seminário 
Docomomo Brasil: interdisciplinaridade e experiências em documentação e preservação do patrimônio recente. Brasília, junho de 2011. Disponível em: http://docomomo.org.br/wp-content/uploads/2016/01/153_PB_OR-Arquiteturado MovimentoModerno-ART_dafne_mendonca.pdf. Acesso em: 06/11/2019

MENGUE, Priscila, Antiga sede da MTV, Assembleia e outros 30 imóveis são tombados em SP. Jornal: O Estado de S. Paulo, 30 de maio de 2019. Disponível em: https://sao-paulo.estado.com.br/noticias/geral,antiga-sede-damtv-assembleia-eoutros-30-imoveis-sao-tombados-em-sp,70002849892. Acesso em: 06/11/2019

SEGAWA, H, Arquiteturas no Brasil: 1900-1990. Edição: 3ª. São Paulo: Edusp, 1998. $232 \mathrm{p}$.

Enviado: Novembro, 2019.

Aprovado: Dezembro, 2019. 